\title{
Improved RE31 Analogues Containing Modified Nucleic Acid Monomers: Thermodynamic, Structural and Biological Effects
}

\author{
Weronika Kotkowiak $^{1, *}$, Jesper Wengel ${ }^{2}$, Chris J. Scotton ${ }^{3}$ and Anna Pasternak ${ }^{1, *}$ \\ ${ }^{1}$ Department of Nucleic Acids Bioengineering, Institute of Bioorganic Chemistry, Polish \\ Academy of Sciences, Noskowskiego 12/14, 61-704 Poznan, Poland \\ ${ }^{2}$ Department of Physics, Chemistry and Pharmacy, Biomolecular Nanoscale Engineering \\ Center, University of Southern Denmark, Campusvej 55, Odense M, 5230, Denmark \\ ${ }^{3}$ Institute of Biomedical and Clinical Science, College of Medicine \& Health, University of \\ Exeter, St Luke's Campus, Exeter, EX1 2LU, U. K.
}

\section{ABSTRACT}

RE31 is a 31-nt DNA aptamer, consisting of the G-quadruplex and a duplex domain, which is able to effectively prolong thrombin time. This article reports on the influence of certain modified nucleotide residues on thermodynamic and biological properties as well as the folding topology of RE31. Particularly, the effect of the presence of canonical nucleosides in unlocked nucleic acid (UNA), locked nucleic acid (LNA) or $\beta$-L-RNA series was evaluated. The studies presented herein show that all modified residues can influence G-quadruplex thermal and biological stability in a position dependent manner. The aptamers modified simultaneously with UNA at the $\mathrm{T}^{15}$ position and LNAs in the duplex part, possess the highest value of melting temperature and a two-fold higher anticoagulant effect. Importantly, RE31 variants modified with canonical nucleosides in UNA, LNA or $\beta$-L-RNA series exhibit unchanged G-quadruplex folding topology. Crucially, introduction of any of the modified residues into RE31 causes prolongation of aptamer stability in human serum.

Keywords: G-quadruplex, thrombin, anticoagulants, DNA, aptamer, unlocked nucleic acids 


\section{INTRODUCTION}

The process of blood coagulation is a chain of reactions, during which serum soluble fibrinogen is converted into insoluble fibrin and forms clots. The aim of this phenomenon is to create a stable haemostatic plug, which will prevent blood from leaking out from blood vessels. ${ }^{1}$ A crucial coagulant factor, which plays the main role in converting fibrinogen into fibrin is thrombin, a serum multifunctional serine protease. ${ }^{2}$ In some cases, including coronary surgery, cancer therapy, and treatment of cardiovascular diseases to name a few, thrombin action is detrimental and needs to be inhibited. Currently, a wide variety of anticoagulant compounds have been identified, such as warfarin, low molecular weight heparin and dabigatran, and DNA aptamers constitute a unique class among them.

One the most widely known DNA aptamer is thrombin binding aptamer (TBA), which was discovered in 1992 by Louis Bock by in vitro selection. ${ }^{3}$ The 15-nt DNA oligonucleotide folds into an antiparallel, intramolecular G-quadruplex structure with a chair-like conformation. The TBA core consists of the G-tetrads linked by one TGT and two TT edge-wise loops (Figure 1A). ${ }^{4}$ From the beginning of its discovery, TBA was thought to have interesting anticoagulant properties, although it failed in the clinical trials due to substantial therapeutic dose needed to achieve therapeutic effect. This, however, did not discourage scientists from seeking to take advantage of TBA favorable properties such as cost-effective and efficient chemical synthesis, small molecule size and reversibility of action. ${ }^{5}$ Significant improvements in TBA anticoagulant activity have been achieved by introduction of chemical modifications ${ }^{6-11}$ and additional nucleotide residues into its sequence. ${ }^{12}$ 
A

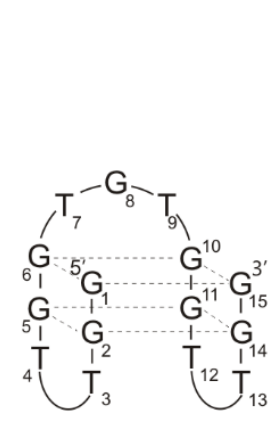

B

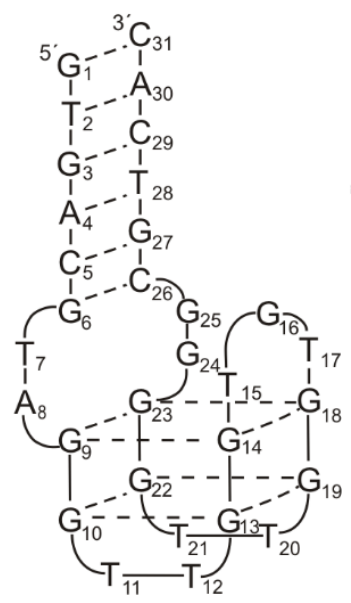

C

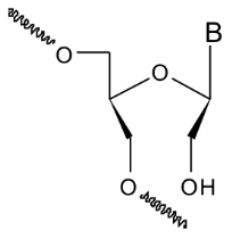

E

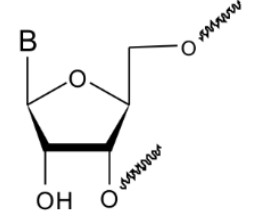

Figure 1. Structure of (A) thrombin binding aptamer (TBA), (B) RE31, (C) UNA nucleotide monomer, (D) LNA nucleotide monomer and (E) $\beta$-L-RNA nucleotide monomer.

One of the first attempts to create longer oligonucleotide constructs based on the TBA sequence were made by Ikebukuro and co-workers. ${ }^{13}$ They designed a pool of 31-nt oligonucleotides consisting of the prototype TBA G-quadruplex structure and five-base-pair long duplex regions at the $5^{\prime}$ and $3^{\prime}$ ends connected by three-nucleotide long loops, which exhibited higher than TBA inhibitory activity. In 2009, following these previous studies, Mazurov and co-workers designed RE31, ${ }^{14}$ a 31-nt DNA oligomer, which consists of the G-quadruplex and a duplex domain linked together by 4 nucleotides (Figure 1B). ${ }^{15}$ The G-quadruplex part is 15-nt fragment, which possesses identical to the TBA sequence and structure, while the duplex domain is composed of 6 pairs of complementary nucleotides. RE31 is able to prolong thrombin time more effectively than TBA does. ${ }^{15}$ According to crystallographic data, it was shown that the duplex part of RE31 gradually transforms into the G-quadruplex structure with similarly oriented helical axes of the two fragments. ${ }^{16}$ Therefore, the aptamer is believed to adopt a rod-like shape, which prevents simultaneous binding of both RE31 regions to a thrombin molecule. The binding to target protein involves only the G-quadruplex region and is assigned to take place in exosite I. Nevertheless, the duplex part, to 
a certain extent, can provide additional contacts with symmetry-related thrombin molecules, which result in RE31 increased affinity for its target protein compared with TBA. ${ }^{15,17}$

Unlocked nucleic acid (UNA) is an RNA analog, which contains acyclic sugar moiety. ${ }^{18}$ The lack of a bond between the $\mathrm{C} 2^{\prime}$ and $\mathrm{C} 3^{\prime}$ atoms of the ribose ring results in increased flexibility of this monomer (Figure 1C) compared with the regular nucleoside, due to the enhanced rotational freedom of $\mathrm{C}-\mathrm{C}$ bonds. It was previously reported that UNAs are able to improve the aptamer thermodynamic stability and anticoagulant activity in a position-dependent manner. ${ }^{6,19}$ On the other hand, introduction of UNAs into RNA or DNA helix causes an unfavorable changes of thermodynamic parameters. ${ }^{20,21}$

Locked nucleic acid (LNA), in contrast, is a type of modification of nucleotide residues that demonstrate a favorable influence on duplex thermodynamic stability. LNA is an RNA analog, which possesses an additional methylene bridge connecting the $\mathrm{C} 2$ ' and $\mathrm{C}^{\prime}$ ' atoms of the ribose ring (Figure 1D). ${ }^{22,23}$ Oligonucleotides containing LNA modifications form duplexes with increased thermal stabilities and improved selectivity according to the Watson-Crick base pairing rules. ${ }^{22}$ This findings refers to DNA, RNA as well as to DNA-RNA mixed helical fragments..$^{23,24}$ On the other hand, introduction of LNA into the G-quadruplex can destabilize its structure and decrease biological activity. ${ }^{8,25}$

The $\beta$-L-RNA derivative is characterized by inversion of the ribose ring stereogenic centers configuration (Figure 1E). ${ }^{26}$ Therefore, introduction of $\beta$-L-RNAs into duplex fragments results in the occurrence of a left-handed double helical structure. Homochiral L-RNA duplexes display unchanged thermodynamic stability in comparison to their naturally occurring $\beta$-D-RNA counterparts. ${ }^{27}$ What is more, introduction of $\beta$-L-RNAs into double stranded oligonucleotides improves their biological stability in human serum and resistance towards nucleolytic degradation. ${ }^{26}$ 
Herein, the influence of modified nucleotide residues introduced into RE31 molecule was presented for the first time. In more details, the consequences of single and multiple substitutions of UNA-A, UNA-C, UNA-G, UNA-U, LNA-A, LNA-G, LNA-T, $\beta$-L-RNA-A, $\beta$-L-RNA-C, $\beta$-L-RNA-G and $\beta$-L-RNA-U on RE31 folding topology were examined. Moreover, the thermal and biological stability of the analyzed aptamers substituted with the modified nucleoside residues was assessed, as well as the anticoagulant properties of the novel RE31 variants were determined.

\section{RESULTS AND DISCUSSION}

\section{Thermal denaturation measurements}

Thermal denaturation measurements were employed to verify the influence of single or multiple substitution of the nucleoside residues in UNA, LNA and $\beta$-L-RNA series on RE31 thermal stabilities. This technique allows for recording changes in absorbance of the analyzed probe due to temperature increase. ${ }^{28} \mathrm{~A}$ valuable parameter, which allows for designation of oligonucleotide thermal stability is melting temperature $\left(\mathrm{T}_{\mathrm{M}}\right)$ i.e. the temperature at which unfolded and structuralized forms of nucleic acids are in equal proportions. G-quadruplex thermodynamic studies were performed at $295 \mathrm{~nm}$ wavelength and characterized by the presence of hypochromic effect. This phenomenon relies on a decrease in absorbance connected with temperature increase and is a result of disappearance of interactions between G-tetrads-forming guanosine residues.

Herein, the attempts to increase the thermal stability of RE31 aptamer via modified residues introduction into its G-quadruplex core are presented for the first time. It was previously proven that introduction of UNA-U residues into the $\mathrm{T}^{3}, \mathrm{~T}^{7}$ and $\mathrm{T}^{12}$ positions of TBA increases its thermal stability. ${ }^{6}$ Based on this and taking into consideration the structural similarities of the G-quadruplex region of RE31 to the TBA molecule, the positions $\mathrm{T}^{11}, \mathrm{~T}^{15}$ 
and $\mathrm{T}^{20}$ (equivalent to $\mathrm{T}^{3}, \mathrm{~T}^{7}$ and $\mathrm{T}^{12}$ in TBA) were chosen as positions of substitution of the nucleoside residues in the UNA series. Melting analysis revealed that replacement of thymine at position $\mathrm{T}^{11}$ and $\mathrm{T}^{20}$ with UNA-U causes a minor increase in thermal stability of RE31 variants in respect to unmodified aptamer $\left(\Delta \mathrm{T}_{\mathrm{M}}\right.$ for aptamers $\mathrm{O} 1$ and $\mathrm{O} 6$ was 2.3 and $1.0^{\circ} \mathrm{C}$, respectively, Table 1). A similar stabilization was observed for oligomers $\mathrm{O} 2$ - O5 possessing UNA-A, UNA-C, UNA-G, UNA-U substitution at $\mathrm{T}^{15}$ position. In this case the $\Delta \mathrm{T}_{\mathrm{M}}$ values were in the range of $1.8-2.8{ }^{\circ} \mathrm{C}$. Considerable improvement in thermal stability was achieved via simultaneous substitution of thymidine at $\mathrm{T}^{11}, \mathrm{~T}^{15}$ and $\mathrm{T}^{20}$ positions by UNA-U residues ( $\Delta \mathrm{T}_{\mathrm{M}}$ for $\mathrm{O} 7$ was equal to $5.4^{\circ} \mathrm{C}$ ). Currently, there are no literature reports concerning the influence of modified residues on RE31 chemical and biological properties, however the structural similarities of this region to the TBA molecule allow for drawing certain comparisons. The above data are consistent with our previous reports indicating beneficial influence of introduction of UNA-U at $\mathrm{T}^{3}, \mathrm{~T}^{7}$ and $\mathrm{T}^{12}$ or other UNAs at $\mathrm{T}^{7}$ on TBA thermal stability (these positions are equivalent to $\mathrm{T}^{11}, \mathrm{~T}^{15}$ and $\mathrm{T}^{20}$ positions in RE31). ${ }^{6,19}$ Likewise in the TBA case, the favorable effect of UNAs at position $\mathrm{T}^{15}$ is most probably a consequence of increased flexibility or the presence of additional $2^{\prime}$ hydroxyl group. Thus, the type of heterocyclic base at position $\mathrm{T}^{15}$ seems to be negligible for stabilization of G-quadruplex structure. What is more, the lack of involvement in the intramolecular contacts of positions $\mathrm{T}^{11}$, $\mathrm{T}^{15}$, and $\mathrm{T}^{20}$ makes them tolerant to chemical modification. ${ }^{16}$

The characteristic structure of RE31 gives additional opportunities to increase its thermal stability via introduction of modified residues into the duplex fragment. It was previously proven that introduction of LNA residues into DNA or RNA duplexes increases their thermal stability and improves selectivity in comparison to the corresponding unmodified reference. ${ }^{23,29}$ What is more, it has been suggested that the most potent utilization of LNAs is through alternate spacing with unmodified nucleotides with the first LNA located at the 
penultimate position from the $5^{\prime}$ duplex end. ${ }^{30}$ In the light of the above data, the $\mathrm{T}^{2}, \mathrm{~A}^{4}, \mathrm{G}^{6}$ and $\mathrm{A}^{8}$ residues in RE31 compound were replaced by their LNA counterparts $(\mathrm{O} 8)$, what results in a melting temperature increase by $10.8^{\circ} \mathrm{C}$ (Table 1). Simultaneous presence of LNAs in duplex fragments and one of UNAs at $\mathrm{T}^{15}$ position also caused a significant rise in thermal stability in comparison to RE31 variants possessing only UNAs at $\mathrm{T}^{15}$ (the $\Delta \mathrm{T}_{\mathrm{M}}$ values for $\mathrm{O} 9-\mathrm{O} 12$ were in the range $9.2-12.6{ }^{\circ} \mathrm{C}$ ). In contrast, the $\beta$-L-RNAs are said to have no influence on duplex stability, but exert notably protective effect for helical fragments against nucleolytic degradation. ${ }^{27}$ Therefore, the impact on the aptamer thermal parameters was studied following introduction of modified nucleotide residues in $\beta$-L-RNA series into RE31 helix and linker fragment $\left(\mathrm{T}^{2}-\mathrm{A}^{8}\right.$ and $\left.\mathrm{G}^{24}-\mathrm{A}^{30}\right)$. The achieved results stay in accordance with previously published data. The increase in G-quadruplex melting temperature was modest and $\Delta \mathrm{T}_{\mathrm{M}}$ for O13 was equal to $1.6^{\circ} \mathrm{C}$ (Table 1$)$.

\section{CD spectroscopy}

Circular dichroism (CD) spectroscopy is a useful technique, which provides information about nucleic acids conformation and folding topology, based on the different absorbance of circularly polarized light. ${ }^{31}$ The characteristic CD spectrum is a result of different spatial orientation of optically active nucleotide residues in certain nucleic acid structures and gives information about folding topology of G-quadruplex. Based on experimental data analysis, there are distinguished two folding topologies for G-quadruplex: parallel and antiparallel. ${ }^{32,33}$ The G-quadruplex with parallel folding topology has all strands oriented in the same direction and is characterized by CD pattern with one positive signal near $260 \mathrm{~nm}$ and one negative around $240 \mathrm{~nm}$. In contrast, the CD spectra for the antiparallel G-quadruplex folding include one maximum near $290 \mathrm{~nm}$ and one minimum around $260 \mathrm{~nm}$. It was previously reported that the CD spectrum for RE31 displays a shape, which is characteristic for antiparallel folding 
topology with two positive CD bands near 245 and $295 \mathrm{~nm}$ and one negative signal around 265 nm. ${ }^{17,34}$

The CD spectra for oligomers O1-O13 containing one or more nucleoside residues in UNA, LNA and $\beta$-L-RNA series were recorded to determine the influence of certain modifications on aptamer conformation. All RE31 variants displayed the typical pattern for an antiparallel G-quadruplex structure with two maxima near 245 and $295 \mathrm{~nm}$ and one minimum around $265 \mathrm{~nm}$ (Figure 2A and 2B). However, a lack of positive band around $245 \mathrm{~nm}$ was observed for $\mathrm{O} 13$, which could be a consequence of a different chirality or stacking type. The CD spectra indicate that modified RE31 variants fold into antiparallel G-quadruplex topology, which is comparable to unmodified aptamer at physiological temperature ,

A

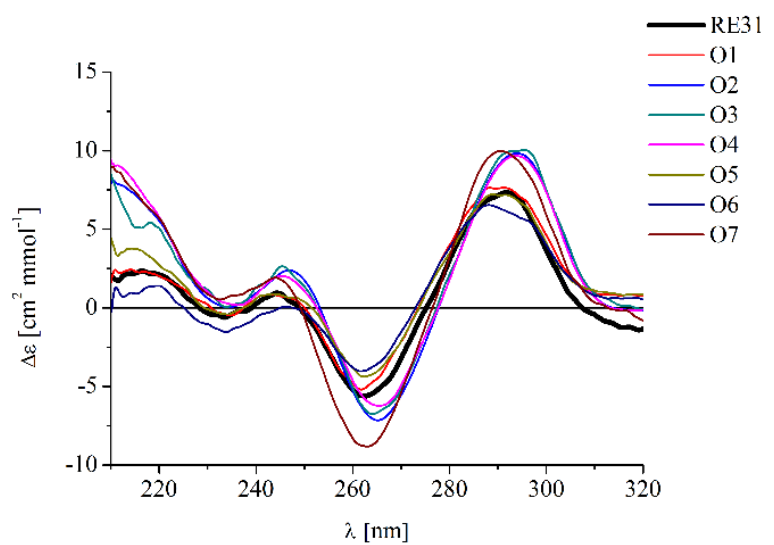

$\mathrm{C}$

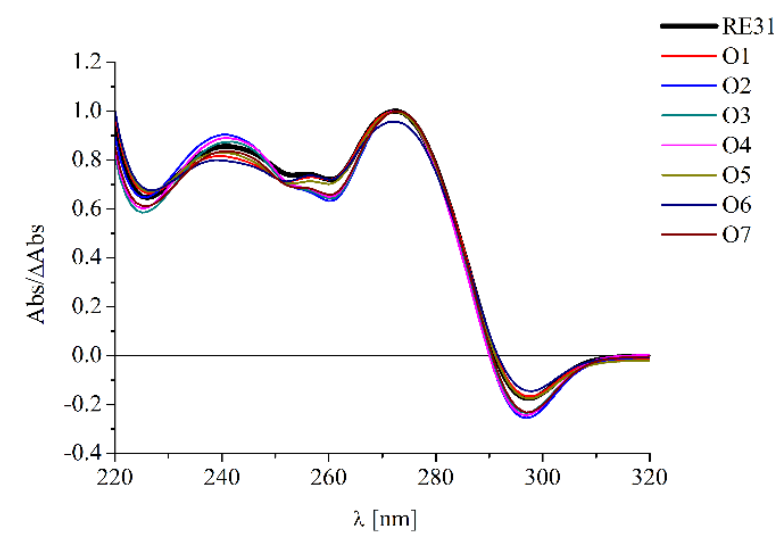

$\mathrm{B}$

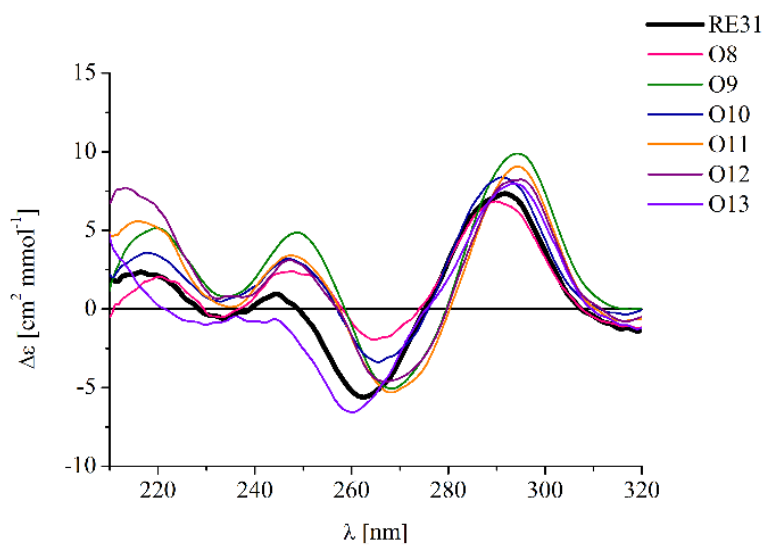

$\mathrm{D}$

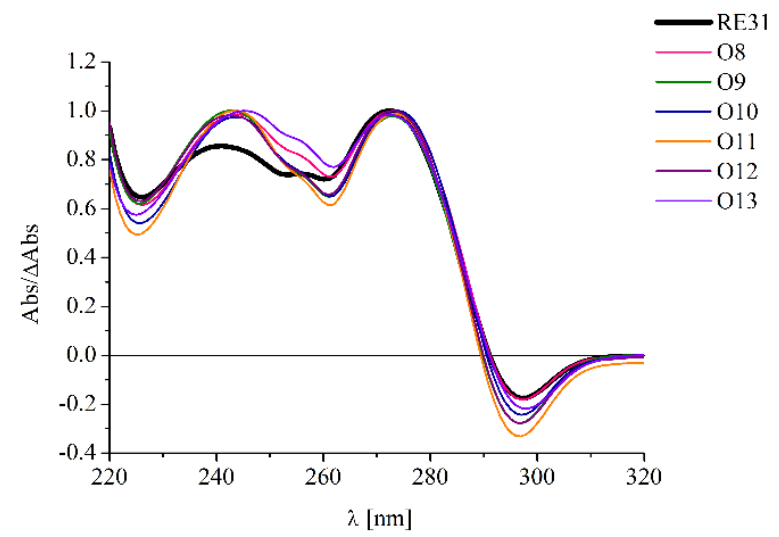


Figure 2. Circular dichroism spectra (A, B) and thermal difference spectra (C, D) of unmodified RE31 (black, bold line) and RE31 variants modified with UNA-U at $\mathrm{T}^{11}$ (O1, red line), UNA-A at $\mathrm{T}^{15}\left(\mathrm{O} 2\right.$, blue line), UNA-C at $\mathrm{T}^{15}\left(\mathrm{O} 3\right.$, dark cyan line), UNA-G at $\mathrm{T}^{15}(\mathrm{O} 4$, magenta line), UNA-U at $\mathrm{T}^{15}$ (O5, dark yellow line), UNA-U at $\mathrm{T}^{20}$ (O6, navy blue line), UNA-U at $\mathrm{T}^{11}, \mathrm{~T}^{15}$, $\mathrm{T}^{20}\left(\mathrm{O} 7\right.$, dark red line), LNAs at $\mathrm{T}^{2}, \mathrm{~A}^{4}, \mathrm{G}^{6}, \mathrm{~A}^{8}\left(\mathrm{O} 8\right.$, pink line), LNAs at $\mathrm{T}^{2}, \mathrm{~A}^{4}, \mathrm{G}^{6}, \mathrm{~A}^{8}$ and UNA-A at $\mathrm{T}^{15}$ (O9, olive line), LNAs at $\mathrm{T}^{2}, \mathrm{~A}^{4}, \mathrm{G}^{6}, \mathrm{~A}^{8}$ and UNA-C at $\mathrm{T}^{15}$ (O10, dark blue line), LNAs at $T^{2}, A^{4}, G^{6}, A^{8}$ and UNA-G at $T^{15}\left(\mathrm{O} 11\right.$, orange line), LNAs at $T^{2}, A^{4}, G^{6}, A^{8}$ and UNA-U at $\mathrm{T}^{15}$ (O12, purple line), $\beta$-L-RNA at $\mathrm{T}^{2}-\mathrm{A}^{8}$ and $\mathrm{G}^{24}-\mathrm{A}^{30}$ (O13, violet line).

\section{Thermal difference spectra}

Thermal difference spectra (TDS) are considered to be complementary to CD spectroscopy, which allow to evaluate nucleic acid structures in solution. ${ }^{35}$ Various structures of nucleic acid possess subtle alterations in stacking interactions, which are reflected by characteristic TDS patterns.

The TDS profiles recorded for oligomers O1-O13 containing single or multiple substitution of the nucleoside residues in UNA, LNA and $\beta$-L-RNA series were characterized by TDS pattern with two positive peaks near 240 and $270 \mathrm{~nm}$ and a negative peak around 295 $\mathrm{nm}$ (Figure 2C and 2D). Herein, for the first time the TDS profiles for aptamer RE31 and its modified variants are published. Nevertheless, based on similarities to previously published data concerning the TDS patterns of unmodified TBA (characterized by presence of two maxima around 240 and $270 \mathrm{~nm}$ and two minima near 260 and $295 \mathrm{~nm}$ ), it can be assumed that these spectral profiles are characteristic of an antiparallel G-quadruplex structure. ${ }^{6}$ Thus, according to TDS patterns it can be concluded that the presence of modified nucleotides in UNA, LNA or $\beta$-L-RNA series within RE31 has no influence on the overall folding topology of G-quadruplex structure. The results remain in compliance with the circular dichroism and thermodynamic studies. 


\section{Thrombin time assay}

Thrombin time assay was employed to verify the influence of nucleotide residues in UNA, LNA or $\beta$-L-RNA series into RE31 on its inhibitory activity towards human thrombin. The main principle of the test is based on thrombin ability to convert plasma-soluble fibrinogen into insoluble fibrin, what results in occurrence of blood clots. The parameter that correlates to the process is thrombin time defined as the time, after which fibrin clot occurs following the addition of exogenous thrombin to blood plasma. Herein, the anticoagulant properties of RE31 variants were compared by analysis of the anticoagulant effect (AE). The AE parameter is defined as differences in the clotting times for (i) plasma with exogenous thrombin and oligonucleotides and (ii) plasma with exogenous thrombin only. ${ }^{19}$

It was previously reported that introduction of UNA residues into TBA molecule has particularly beneficial influence on its biological activity level. ${ }^{6,19}$ Taking into account the structural similarities between G-quadruplex region of RE31 and TBA, ${ }^{16}$ we decided to verify whether it is possible to improve the aptamer anticoagulant properties through UNA-substitution. The measurements were performed at $0.165 \mu \mathrm{M}$ concentration of each RE31 variant. The most favorable effect was achieved via introduction of UNA residues into $\mathrm{T}^{15}$ position of RE31. The UNA-C substitution at $\mathrm{T}^{15}$ position of RE31 turned out to be particularly beneficial (the $\mathrm{AE}$ for $\mathrm{O} 3$ was $17.08 \mathrm{~s}$, Table 2). The prolongation of thrombin time, in comparison to unmodified RE31, was also possible due to introduction of UNA-G at the $\mathrm{T}^{15}$ position (AE for RE31 and O4 was 11.09 and $12.18 \mathrm{~s}$, respectively). The high tolerance of $\mathrm{T}^{15}$ position towards substitution with UNA residues can be caused by the lack of involvement of the residue at this position in the direct interactions with thrombin or in an energetically favorable intramolecular interactions. ${ }^{16}$ Therefore, the increased flexibility in this loop fragment might result in more favorable arrangement of thrombin-RE31 complex. Surprisingly, the introduction of UNA-U at $\mathrm{T}^{15}$ position causes some decrease of RE31 anticoagulant activity 
(AE for O5 was $9.66 \mathrm{~s}$ ). Moreover, the presence of UNA-U within the aptamer loops resulted in notable reduction of RE31 anticoagulant potential. The AE parameter measured for aptamers modified with UNA-U residues at positions $\mathrm{T}^{11}(\mathrm{O} 1)$ and $\mathrm{T}^{20}(\mathrm{O} 6)$ was 6.87 and $4.27 \mathrm{~s}$, respectively (). The above effect can be explained by involvement of these two residues in formation of hydrogen bonds between RE31 molecule and thrombin. ${ }^{16}$ Therefore, the increased flexibility of the RE31 loops via insertion of UNA residues perturbs favorable intermolecular interactions. The simultaneous introduction of UNA-U at positions $\mathrm{T}^{11}, \mathrm{~T}^{15}$ and $\mathrm{T}^{20}$ provoked the most significant reduction of RE31 anticoagulant properties (the AE for O7 was $0.65 \mathrm{~s}$ ).

The introduction of LNA and $\beta$-L-RNA residues into aptamer duplex fragment results in decreased $\mathrm{AE}$ values in comparison to unmodified aptamer (AE for O8 and O13 was 10.09 and $8.13 \mathrm{~s}$, respectively, Table 2). Surprisingly, this trend could be reversed through additional incorporation of UNA residues into $\mathrm{T}^{15}$ position. The most favorable effect was measured for aptamer O9 containing both, LNA and UNA-A residues (AE was $23.27 \mathrm{~s}$ ). An almost equally beneficial outcome was found in case of coexistence of canonical LNAs at $T^{2}, A^{4}, G^{6}, A^{8}$ positions and UNA-C at $\mathrm{T}^{15}$ position, the $\mathrm{AE}$ value for $\mathrm{O} 10$ was $21.58 \mathrm{~s}$. Moderate improvement in anticoagulant properties was observed for oligomers $\mathrm{O} 11$ and $\mathrm{O} 12$ containing at the same time canonical LNAs at $\mathrm{T}^{2}, \mathrm{~A}^{4}, \mathrm{G}^{6}, \mathrm{~A}^{8}$ positions and UNA-G or UNA-U at $\mathrm{T}^{15}$ position (the AE were $14.10 \mathrm{~s}$ and $10.68 \mathrm{~s}$, respectively).

Based on data analysis of thrombin time assay conducted for the most favorable RE31 variants with its various solutions $(0.0825,0.165,0.330,0.495,0.660,0.825$ and $1 \mu \mathrm{M})$ it could be concluded that the anticoagulant effect strictly depends on aptamers concentration. Noteworthy, it is possible to improve the effectiveness of action of particular RE31 variant via increase of oligonucleotide concentration. What is more, the results show that aptamers $\mathrm{O} 3$ and $\mathrm{O} 4$ containing single UNA residue at $\mathrm{T}^{15}$ position were characterized by greater AE value than their counterpart modified simultaneously with LNAs in duplex fragment and UNAs at $\mathrm{T}^{15}$ 
position (oligonucleotides O10 and O11, Figure 3). Aptamers O2 and O9 (modified with single UNA-A at $\mathrm{T}^{15}$ or LNAs in duplex fragment and UNA-A at $\mathrm{T}^{15}$, respectively) constituted the only exception of this rule (Figure 3). The sudden increase of anticoagulant properties of some RE31 variants, especially aptamer O3 (Figure 3), in respect to others could be also observed. This phenomenon may be attributable to differences in specificity and competition of interactions between the oligonucleotides and thrombin versus remaining plasma proteins. Different chemical modifications most probably modulate both kinds of interactions in a different way, which results in differences in the dose-response pattern of each oligonucleotide.

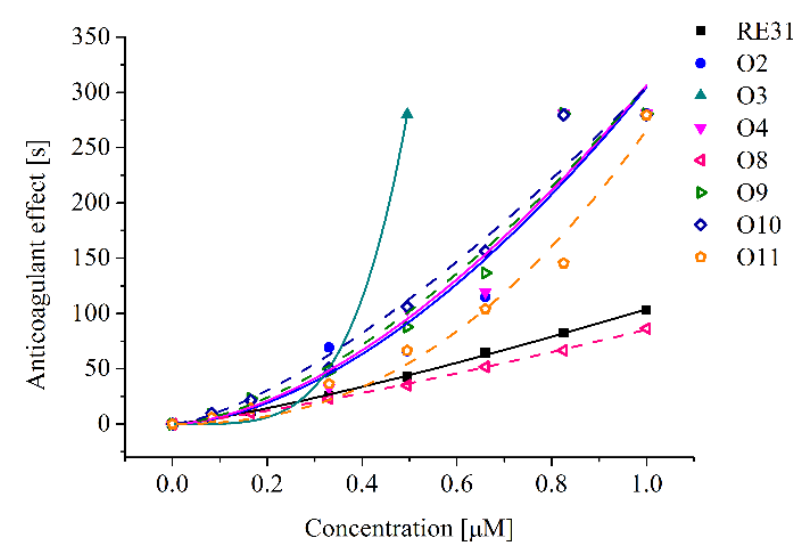

Figure 3. Concentration dependence of anticoagulant effect of unmodified RE31 (black symbol) and RE31 variants modified with UNA-A at $\mathrm{T}^{15}\left(\mathrm{O} 2\right.$, blue symbol), UNA-C at $\mathrm{T}^{15}(\mathrm{O} 3$, dark cyan symbol), UNA-G at $\mathrm{T}^{15}\left(\mathrm{O} 4\right.$, magenta symbol), LNAs at $\mathrm{T}^{2}, \mathrm{~A}^{4}, \mathrm{G}^{6}, \mathrm{~A}^{8}(\mathrm{O} 8$, pink, open symbol), LNAs at $\mathrm{T}^{2}, \mathrm{~A}^{4}, \mathrm{G}^{6}, \mathrm{~A}^{8}$ and UNA-A at $\mathrm{T}^{15}$ (O9, olive, open symbol), LNAs at $\mathrm{T}^{2}, \mathrm{~A}^{4}, \mathrm{G}^{6}, \mathrm{~A}^{8}$ and UNA-C at $\mathrm{T}^{15}\left(\mathrm{O} 10\right.$, dark blue, open symbol), LNAs at $\mathrm{T}^{2}, \mathrm{~A}^{4}, \mathrm{G}^{6}, \mathrm{~A}^{8}$ and UNA-G at $\mathrm{T}^{15}$ (O11, orange, open symbol).

In general, the data analysis shows a favorable influence of simultaneous substitution of LNA residues in duplex fragment and UNA-A, UNA-C or UNA-G at $\mathrm{T}^{15}$ position on anticoagulant properties of RE31 variants. In addition, aptamers possessing UNA-A, UNA-C 
or UNA-G instead of $\mathrm{T}^{15}$ exhibited greater AE values than unmodified RE31. The observed effect is strictly concentration dependent.

\section{Amidolytic assay}

Thrombin molecule consists of four structural domains: the active site, two anion-binding exosites (I and II) and $\mathrm{Na}^{+}$-binding site. ${ }^{36}$ The active site is directly involved in hydrolysis of substrate peptide bond. The two anion-binding exosites are the most positively charged parts of thrombin, where binding of its substrates and activity modulator takes place. It was previously reported that both TBA and RE31 bind to exosite $\mathrm{I} .{ }^{14}$ Herein, the amidolytic assay was applied to assess the influence of modified nucleotides on RE31 aptamer binding to thrombin molecule. It is a useful method, which allows to determine the exact localization of interaction based on thrombin proteolytic activity. In situation of thrombin catalytic center accessibility, the peptide bond of chromogenic substrate H-D-Phe-Pip-Arg-pNA is hydrolyzed and p-nitroaniline is generated, what results in appearance of yellow color of probes. Therefore, the thrombin catalytic activity can be determined via investigation of the change in the sample absorbance. H-D-Phe-Pip-Arg-pNA binds to the thrombin active site even when other functional domains are involved in interactions with enzyme substrates or its inhibitors. The calculation of the percentage of thrombin activity maintenance (At) was used to determine thrombin ability to hydrolyze short peptide H-D-Phe-Pip-Arg-pNA in the presence of tested RE31 variants. The At parameter value of $100 \%$ corresponds to the absorbance for the thrombin solution measured at $405 \mathrm{~nm}$.

The highest value of thrombin activity was measured for unmodified RE31 and its variants containing UNA-C $(\mathrm{O} 3)$ and UNA-G $(\mathrm{O} 4)$ at $\mathrm{T}^{15}$ position or simultaneously UNA-G at position $\mathrm{T}^{15}$ and canonical LNA residues in duplex part (O11) (Figure 4). The similar effect was noted for aptamers modified with UNA-U at position $\mathrm{T}^{11}(\mathrm{O} 1)$ or simultaneously at $\mathrm{T}^{11}$, $\mathrm{T}^{15}$ and $\mathrm{T}^{20}$ positions $(\mathrm{O} 7)$ or $\beta$-L-RNA residues in duplex part (O13, Figure 4$)$. The At 
parameter extended $100 \%$ for these RE31 variants. The remaining RE31 variants were characterized by a minor decrease in thrombin activity maintenance levels $(90 \%<$ At $<100 \%)$. The significance level of differences in thrombin activity in the presence of analyzed RE31 variants was determined via statistical analysis by Student t-test (data not shown). In all cases, the p-value was above 0.05 , thus the observed differences in At values were not statistically significant. Taking together, the data demonstrate that thrombin maintains its ability to hydrolyze peptide substrate H-D-Phe-Pip-Arg-pNA in presence of the RE31 variants, and therefore it can be concluded that the aptamers inhibitory properties are a results of binding to exosite I of thrombin molecule.

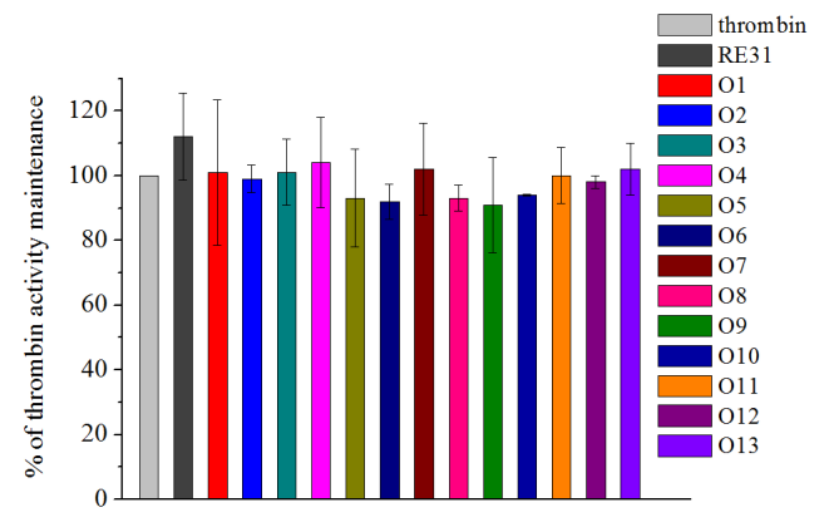

Figure 4. The amidolytic activity of thrombin in the presence of unmodified RE31 (black bar) and RE31 variants modified with UNA-U at $\mathrm{T}^{11}\left(\mathrm{O} 1\right.$, red bar), UNA-A at $\mathrm{T}^{15}(\mathrm{O} 2$, blue bar), UNA-C at $\mathrm{T}^{15}\left(\mathrm{O} 3\right.$, dark cyan bar), UNA-G at $\mathrm{T}^{15}\left(\mathrm{O} 4\right.$, magenta bar), UNA-U at $\mathrm{T}^{15}(\mathrm{O} 5$, dark yellow bar), UNA-U at $\mathrm{T}^{20}$ (O6, navy blue bar), UNA-U at $\mathrm{T}^{11}, \mathrm{~T}^{15}, \mathrm{~T}^{20}(\mathrm{O} 7$, dark red bar), LNAs at $T^{2}, A^{4}, G^{6}, A^{8}\left(O 8\right.$, pink bar), LNAs at $T^{2}, A^{4}, G^{6}, A^{8}$ and UNA-A at $T^{15}(O 9$, olive bar), LNAs at $\mathrm{T}^{2}, \mathrm{~A}^{4}, \mathrm{G}^{6}, \mathrm{~A}^{8}$ and UNA-C at $\mathrm{T}^{15}\left(\mathrm{O} 10\right.$, dark blue bar), LNAs at $\mathrm{T}^{2}, \mathrm{~A}^{4}, \mathrm{G}^{6}, \mathrm{~A}^{8}$ and UNA-G at $\mathrm{T}^{15}\left(\mathrm{O} 11\right.$, orange bar), LNAs at $\mathrm{T}^{2}, \mathrm{~A}^{4}, \mathrm{G}^{6}, \mathrm{~A}^{8}$ and UNA-U at $\mathrm{T}^{15}(\mathrm{O} 12$, purple bar), $\beta-\mathrm{L}-\mathrm{RNA}$ at $\mathrm{T}^{2}-\mathrm{A}^{8}$ and $\mathrm{G}^{24}-\mathrm{A}^{30}(\mathrm{O} 13$, violet bar). 


\section{Surface plasmon resonance}

The determination of the strength of interactions between thrombin and RE31 variants was conducted using real-time surface plasmon resonance (SPR) spectroscopy. This optical technique allows calculation of the dissociation constant (Kd value) according to the change in refractive index. The conventional SPR measurement requires immobilization of one of the binding components on the metallic surface of the sensor chip whilst the other is flowed across the sensor surface. ${ }^{37}$ Herein, the group of the most stable and potent RE31 variants were chosen for the binding affinity studies.

The most favorable Kd values, in comparison to unmodified RE31 (for which the Kd value was $1.34 \mathrm{nM}$, Table 2), were obtained for $\mathrm{O} 3$ modified with UNA-C residues at position $\mathrm{T}^{15}$ (the Kd value was $0.43 \mathrm{nM}$ ). Kd values measured for RE31 variants modified with UNA-A, UNA-G and UNA-U at $\mathrm{T}^{15}$ position were higher but still more favorable than for unmodified RE31 (the $\mathrm{Kd}$ values for $\mathrm{O} 2, \mathrm{O} 4$ and $\mathrm{O} 5$ were $0.76,0.68$ and $0.75 \mathrm{nM}$, respectively). The introduction of LNA residues into the duplex fragment of RE31 molecule caused a decrease in the strength of thrombin-RE31 interactions (the Kd value for O8 was $1.75 \mathrm{nM}$ ). Nevertheless, the unfavorable influence of LNAs could be alleviated by the presence of UNA-A or UNA-C at $\mathrm{T}^{15}$ position (the Kd values for $\mathrm{O} 9$ and $\mathrm{O} 10$ were 1.15 and $0.90 \mathrm{nM}$, respectively).

In general, the Kd values did not directly correspond with the thrombin test results. This is most probably due to the complexity of blood coagulation processes and indicates that the dissociation constant parameter alone is not sufficient for the assessment of the anticoagulant potential.

\section{Viability in human serum}

Oligonucleotides are rapidly eliminated from the circulation and determination of their biostability in human serum is one the most crucial indicators, which allows for prediction of 
their potential in vivo activity. The widely used measure of half-life $\left(\mathrm{T}_{1 / 2}\right)$, defined as time in which the amount of tested substance decays by half, was employed for determination of biostability of RE31 variants in human serum. Various approaches have been proposed to extend G-quadruplex serum viability and the chemical modification of the aptamer could help solve this issue. ${ }^{19,38}$

Herein, the $\mathrm{T}_{1 / 2}$ values for RE31 variants were designated via incubation in human serum at $37^{\circ} \mathrm{C}$. The RE31 variants (O8-O13) modified with LNA, $\beta$-L-RNA and simultaneously UNA and LNA residues were characterized by the most favorable biological stability. In all cases, $\mathrm{T}_{1 / 2}$ was longer than $1440 \mathrm{~min}$ in comparison to $364 \mathrm{~min}$ for unmodified RE31 (Table 2). The $\mathrm{T}^{15}$ substitution by UNA residues also improved the aptamer biostability. Although, in this instance the $\mathrm{T}_{1 / 2}$ for UNA-A (O2) and UNA-C (O3) was equal to $1062 \mathrm{~min}$ and for UNA-G (O4) and UNA-U (O5) was 1047 and 1018 min, respectively. Only a slightly increased biological stability was observed for $\mathrm{O} 6$ containing UNA-U at $\mathrm{T}^{20}$ position or $\mathrm{O} 7$ possessing simultaneously UNA-U at $\mathrm{T}^{11}, \mathrm{~T}^{15}$ and $\mathrm{T}^{20}$ positions ( $\mathrm{T}_{1 / 2}$ was 524 and $538 \mathrm{~min}$, respectively). The achieved results correspond with previously published literature data stating that DNA G-quadruplexes modified with nucleotide residues in UNA series are characterized by extended in vitro stability in serum. ${ }^{38}$ The data presented here further support and extend the current state of knowledge in the field. The introduction of LNA residues may provide a convenient and effective tool to extend DNA G-quadruplex viability in human serum.

\section{CONCLUSIONS}

In this paper, examples of RE31 variants possessing artificial nucleotide residues have been presented for the first time, along with comprehensive thermodynamic and biological studies of RE31 variants modified with nucleotide residues in UNA, LNA and $\beta$-L-RNA series.

The most favourable influence on RE31 thermal stability had LNAs in the duplex fragment or a combination of LNAs in the helix and UNAs at $\mathrm{T}^{15}$ (O8 - O12). Substantial 
improvement was also achieved via ternary substitution of $\mathrm{T}^{11}, \mathrm{~T}^{15}$ and $\mathrm{T}^{20}$ positions by UNA-U (O7). For the rest of the aptamers, only a minor stabilizing effect was observed. The results of structural studies confirmed that the overall folding topology of RE31 variants containing substitution with modified nucleotide residues at the studied positions was unaffected and that all analyzed aptamers form antiparallel G-quadruplex structure at $37^{\circ} \mathrm{C}$. What is more, it was possible to achieve RE31 derivatives characterized by significantly improved anticoagulant properties via simultaneous introduction of UNAs at $\mathrm{T}^{15}$ position and LNAs at helix fragment (O9 - O11). Slightly smaller but still significant anticoagulant effects were observed for aptamers possessing UNAs substitution at $\mathrm{T}^{15}$ position $(\mathrm{O} 2-\mathrm{O} 4)$. It is worth stressing that all analyzed RE31 variants possessed extended biological stability. Notably, introduction of LNAs and $\beta$-L-RNAs into RE31 helical fragment caused meaningful prolongation of aptamers stability in human serum (O8 and O13). Additionally, it was proven that entire pool of tested RE31 variants exerted their inhibitory activity by binding to thrombin exosite I, but their affinity to target protein was strictly dependent on the type of modification.

The results described herein confirm that both LNA and UNA residues are suitable molecular tools to modulate RE31 thermal and biological stability with preservation or improvement of its anticoagulant properties. These findings provide new insight in the area of application of modified DNA aptamers as promising alternatives to classical antithrombin agents.

\section{EXPERIMENTAL SECTION}

\section{Chemical synthesis of oligonucleotides}

All oligonucleotides were synthesized on an automated RNA/DNA synthesizer using standard phosphoramidite chemistry and commercially available nucleoside phosphoramidites. ${ }^{39}$ The deprotection and purification of unmodified oligoribonucleotides or RE31 variants containing 
nucleotide residues in the UNA, LNA and $\beta$-L-RNA series were performed as it was described previously. ${ }^{20,40,41}$ The purity of oligonucleotides was verified as being above $95 \%$ by $20 \%$ denaturing polyacrylamide gel, and the composition of all oligonucleotides was confirmed by MALDI-TOF mass spectrometry.

\section{UV melting analysis}

Oligonucleotides were dissolved in a buffer containing $100 \mathrm{mM}$ potassium chloride, $20 \mathrm{mM}$ sodium cacodylate and $0.5 \mathrm{mM} \mathrm{Na} \mathrm{N}_{2}$ EDTA, $\mathrm{pH}$ 7.0. Single-stranded oligonucleotide concentrations were calculated based on the absorbance measured above $80{ }^{\circ} \mathrm{C}$ and the extinction coefficients were calculated, using Oligo Calculator (ribotask.com). ${ }^{42}$ The samples were denatured at $95{ }^{\circ} \mathrm{C}$ for $5 \mathrm{~min}$ and then cooled to room temperature overnight. The measurements were performed for nine different concentrations of G-quadruplex in the concentration range of $10^{-5}-10^{-7} \mathrm{M}$. Absorbance versus temperature curves were obtained using the UV melting method at $295 \mathrm{~nm}$ in the temperature range of $4-90{ }^{\circ} \mathrm{C}$ with a heating rate of $0.2{ }^{\circ} \mathrm{C} / \mathrm{min}$ on a JASCO V-650 spectrophotometer equipped with a thermoprogrammer. Melting curves were analyzed and the melting points determined by nonlinear curve fitting using the MeltWin 3.5 software. Melting temperatures calculated for a $10^{-4} \mathrm{M}$ concentration of oligonucleotide are denoted by $\mathrm{T}_{\mathrm{M}}$, and melting points for any other concentration of oligonucleotide are denoted by $\mathrm{T}_{\mathrm{m}}$.

\section{Circular dichroism spectra}

CD spectra were recorded on a JASCO J-815 spectropolarimeter. The oligonucleotides were dissolved in a buffer containing $100 \mathrm{mM}$ potassium chloride, $20 \mathrm{mM}$ sodium cacodylate and $0.5 \mathrm{mM} \mathrm{Na}{ }_{2}$ EDTA, $\mathrm{pH} 7.0$, to achieve a sample concentration of $3.0 \mu \mathrm{M}$. All samples were denatured at $95{ }^{\circ} \mathrm{C}$ for $5 \mathrm{~min}$ and then slowly cooled to room temperature overnight prior to data collection. The spectra were recorded in triplicate at $37^{\circ} \mathrm{C}$ in the $205-320 \mathrm{~nm}$ wavelength 
range. The buffer spectrum was subtracted from the sample spectra. The data analysis was performed using the Origin 8.0 software.

\section{Thermal difference spectra}

The TDS measurements were performed on a JASCO V-650 spectrophotometer equipped with a thermoprogrammer. The oligonucleotides were dissolved in a buffer containing $100 \mathrm{mM}$ potassium chloride, $20 \mathrm{mM}$ sodium cacodylate and $0.5 \mathrm{mM} \mathrm{Na} 2$ EDTA, $\mathrm{pH} 7.0$, to achieve a sample concentration of $0.1 \mu \mathrm{M}$. Absorbance spectra were recorded in triplicate at $4{ }^{\circ} \mathrm{C}$ and $90{ }^{\circ} \mathrm{C}$ in the $220-335 \mathrm{~nm}$ wavelength range. The scan speed was $1000 \mathrm{~nm} / \mathrm{min}$ with a $1 \mathrm{~nm}$ data interval. Thermal difference spectra were obtained by subtraction of the low temperature absorbance spectra from the high temperature absorbance spectra using the Origin 8.0 software. The differential spectra were normalized by dividing the data by its maximum value. ${ }^{35}$

\section{Thrombin time assay}

The thrombin time assay was performed using commercially available Dia-TT kit (DIAGON®) and coagulometer K-3002 Optic. Each RE31 variant was dissolved in $100 \mu 1$ Dia-TT reagent, to achieve a sample concentration of $0.33 \mu \mathrm{M}$. The reaction mixture was incubated at $37^{\circ} \mathrm{C}$ for 5 min and put into sample well of coagulometer K-3002 Optic. Next, $100 \mu 1$ of citrate plasma was added. Each RE31 variant was analyzed using plasma samples derived from five healthy volunteers. The sample from each volunteer was measured twice, and the errors of thrombin time values obtained from the double measurements did not exceed 6\% (Table 2). The anticoagulant effect was obtained by subtraction of the time needed for plasma clotting in the presence of the aptamers from the time needed for clotting of plasma without aptamer. In addition, thrombin time for RE31 variants with the best anticoagulant properties in seven different concentrations: $0.0825,0.165,0.330,0.495,0.660,0.825$, and $1 \mu \mathrm{M}$ was assigned 
using plasma samples derived from three healthy volunteers. Each experiment was repeated twice and the result expressed as mean value.

\section{Surface plasmon resonance}

The value of dissociation constant $\left(\mathrm{K}_{\mathrm{d}}\right)$ for chosen RE31 variants was measured using a Biacore $^{\mathrm{TM}}$ X100 system (GE Healthcare Life Science), human alpha-thrombin solution (Haematologic Technologies, Inc.) and commercially available Biotin CAPture KIT (GE Healthcare Life Science). The 5'-biotinylated oligonucleotides were dissolved in a running buffer - $10 \mathrm{mM}$ phosphate buffered saline $\left(138 \mathrm{mM} \mathrm{NaCl}, 2.7 \mathrm{mM} \mathrm{KCl}, 10 \mathrm{mM} \mathrm{Na} 2 \mathrm{HPO}_{4}\right.$, $1.76 \mathrm{mM} \mathrm{KH}_{2} \mathrm{PO}_{4}, 0.05 \%$ Tween-20, $\mathrm{pH} 7.4$ ) to achieve a sample concentration of $1 \mu \mathrm{M}$. The samples were denatured at $95^{\circ} \mathrm{C}$ for 6 min and then cooled to room temperature overnight. The oligonucleotides were immobilized on a chip surface via the streptavidin-biotin coupling method. The flow rate was set to $30 \mu \mathrm{l} / \mathrm{min}$ and the unbound oligonucleotide was removed by the treatment with $50 \mathrm{mM}$ aqueous $\mathrm{NaOH}$. Next, serially diluted thrombin solution in the concentration range of $12.5-200 \mathrm{nM}$ along with a bovine serum albumin (BSA, Sigma-Aldrich ${ }^{\circledR}$ ) and sample with only running buffer were injected. The measurements were performed at $25{ }^{\circ} \mathrm{C}$. After each run, the system was regenerated by treatment with $50 \mathrm{mM}$ aqueous $\mathrm{NaOH}$. Data analysis was performed using the Biacore X100 Evaluation software and a 1:1 binding mode.

\section{Amidolytic assay}

Amidolytic assay was used to evaluate the ability of human alpha-thrombin (Haematologic Technologies, Inc.) to hydrolyze chromogenic substrate H-D-Phenylalanyl-L-argininep-nitroaniline (H-D-Phe-Pip-Arg-pNA, trade name: S-2238 ${ }^{\mathrm{TM}}$, CHROMOGENIX) in the presence of chosen RE31 variants. The reaction mixture (150 $\mu 1)$, consisting of the chosen RE31 variants $(1 \mu \mathrm{M})$, thrombin $(0.4 \mathrm{U} / \mathrm{ml})$ and reaction buffer $(0.1 \mathrm{M}$ Tris $\mathrm{pH} 8.2,150 \mathrm{mM} \mathrm{NaCl}$, 
$5 \mathrm{mM} \mathrm{KCl}, 0.1 \% \mathrm{BSA}$ ), was incubated at $37^{\circ} \mathrm{C}$ for $5 \mathrm{~min}$. Next, $50 \mu \mathrm{l}$ of $2 \mathrm{mM}$ chromogenic substrate H-D-Phe-Pip-Arg-pNA was added. The amount of released p-nitroaniline was measured at $405 \mathrm{~nm}$ using a microplate reader $\mathrm{xMark}^{\mathrm{TM}}$ (Bio-Rad). Data analysis was performed using Microsoft Excel 2013 software. Each experiment was repeated in triplicate and the result expressed as mean value.

\section{Viability of oligonucleotides in human serum}

The amount of 110 pmol of 5'-FAM labeled oligonucleotides was dissolved in $20 \mu 1$ of 1 x PBS buffer containing $100 \mathrm{mM}$ potassium chloride. The samples were denatured at $90{ }^{\circ} \mathrm{C}$ for $6 \mathrm{~min}$ and then cooled to room temperature overnight. Afterwards, $200 \mu 1$ of human serum from human male AB plasma (Sigma-Aldrich) was added, and the samples were incubated at $37^{\circ} \mathrm{C}$. Aliquots of $5 \mu 1$ were removed after $0,10,20,40,60,120,180$ and 1440 min (for less stable aptamers) or after $0,20,40,60,120,240,480,1440,1680,1920$ and $2880 \mathrm{~min}$ (for more stable aptamers) of incubation and were then mixed with $5 \mu 1$ of a $70 \%$ deionized formamide solution containing $50 \mathrm{mM}$ EDTA and cooled on dry ice to quench the reaction. The samples were loaded on a $12 \%$ denaturing polyacrylamide gel prepared in $1 \times$ TBE buffer. Polyacrylamide gel electrophoresis (PAGE) in denaturing condition was performed in $1 \mathrm{x}$ TBE buffer at $20 \mathrm{~W}$ for $3 \mathrm{~h}$ at room temperature. The resultant gel was imaged and quantified using a Fuji Phosphorimager and MultiGauge Analysis Software.

\section{AUTHOR INFORMATION}

\section{Corresponding Author}

*To whom correspondence should be addressed. Tel: + 48618528 503; Fax: +48 618520 532;

E-mail: apa@ibch.poznan.pl (to A.P.); kawecka@ibch.poznan.pl (to W.K.). 


\section{Author Contributions}

W.K. performed all experiments and wrote the paper. J.W. supervised the SPR measurements. C.J.S. proofed the paper. A.P. performed oligonucleotide synthesis, supervised all the experiments and proofed the paper. All authors have given approval to the final version of the manuscript.

\section{ACKNOWLEDGMENTS}

This work has been supported by the National Science Center [UMO-2015/19/N/NZ5/02246 to W.K., UMO-2013/10/E/NZ1/00741 and UMO-2017/25/B/NZ7/00127 to A.P.] and by the Polish Ministry of Science and Higher Education [27/SN/2018 to W.K.]. We also thank the WILLUM Foundation for funding the Biomolecular Nanoscale Engineering Center (BioNEC; grant number 00007206).

\section{ABBREVIATIONS USED}

$\mathrm{AE}$, anticoagulant effect; At, percentage of thrombin activity maintenance; $\mathrm{Kd}$, dissociation constant; LNA, locked nucleic acid; SPR, surface plasmon resonance; TBA, thrombin binding aptamer; TDS, thermal difference spectra; $\mathrm{T}_{\mathrm{M}}$, melting temperature; $\mathrm{T}_{1 / 2}$, half-life; UNA, unlocked nucleic acid

\section{REFERENCES}

1. Walker, C. P.; Royston, D. Thrombin generation and its inhibition: a review of the scientific basis and mechanism of action of anticoagulant therapies. Br J Anaesth 2002, 88, 848-863.

2. Coppens, M.; Eikelboom, J. W.; Gustafsson, D.; Weitz, J. I.; Hirsh, J. Translational success stories: development of direct thrombin inhibitors. Circ Res 2012, 111, 920-929.

3. Bock, L. C.; Griffin, L. C.; Latham, J. A.; Vermaas, E. H.; Toole, J. J. Selection of singlestranded DNA molecules that bind and inhibit human thrombin. Nature 1992, 355, 564-566.

4. Pica, A.; Russo Krauss, I.; Merlino, A.; Nagatoishi, S.; Sugimoto, N.; Sica, F. Dissecting the contribution of thrombin exosite I in the recognition of thrombin binding aptamer. FEBS $J \mathbf{2 0 1 3}, 280$, 6581-6588.

5. Avino, A.; Fabrega, C.; Tintore, M.; Eritja, R. Thrombin binding aptamer, more than a simple aptamer: chemically modified derivatives and biomedical applications. Curr Pharm Des 2012, 18, 20362047.

6. Pasternak, A.; Hernandez, F. J.; Rasmussen, L. M.; Vester, B.; Wengel, J. Improved thrombin binding aptamer by incorporation of a single unlocked nucleic acid monomer. Nucleic Acids Res 2011, $39,1155-1164$ 
7. Mendelboum Raviv, S.; Horvath, A.; Aradi, J.; Bagoly, Z.; Fazakas, F.; Batta, Z.; Muszbek, L.; Harsfalvi, J. 4-thio-deoxyuridylate-modified thrombin aptamer and its inhibitory effect on fibrin clot formation, platelet aggregation and thrombus growth on subendothelial matrix. J Thromb Haemost 2008, 6, 1764-1771.

8. Bonifacio, L.; Church, F. C.; Jarstfer, M. B. Effect of locked-nucleic acid on a biologically active g-quadruplex. A structure-activity relationship of the thrombin aptamer. Int J Mol Sci 2008, 9, 422-433.

9. Jensen, T. B.; Henriksen, J. R.; Rasmussen, B. E.; Rasmussen, L. M.; Andresen, T. L.; Wengel, J.; Pasternak, A. Thermodynamic and biological evaluation of a thrombin binding aptamer modified with several unlocked nucleic acid (UNA) monomers and a 2'-C-piperazino-UNA monomer. Bioorg Med Chem 2011, 19, 4739-4745.

10. Nallagatla, S. R.; Heuberger, B.; Haque, A.; Switzer, C. Combinatorial synthesis of thrombinbinding aptamers containing iso-guanine. J Comb Chem 2009, 11, 364-369.

11. Borbone, N.; Bucci, M.; Oliviero, G.; Morelli, E.; Amato, J.; D'Atri, V.; D'Errico, S.; Vellecco, V.; Cirino, G.; Piccialli, G.; Fattorusso, C.; Varra, M.; Mayol, L.; Persico, M.; Scuotto, M. Investigating the role of $\mathrm{T} 7$ and $\mathrm{T} 12$ residues on the biological properties of thrombin-binding aptamer: enhancement of anticoagulant activity by a single nucleobase modification. $J$ Med Chem 2012, 55, 10716-10728.

12. Macaya, R. F.; Waldron, J. A.; Beutel, B. A.; Gao, H.; Joesten, M. E.; Yang, M.; Patel, R.; Bertelsen, A. H.; Cook, A. F. Structural and functional characterization of potent antithrombotic oligonucleotides possessing both quadruplex and duplex motifs. Biochemistry 1995, 34, 4478-4492.

13. Ikebukuro, K.; Okumura, Y.; Sumikura, K.; Karube, I. A novel method of screening thrombininhibiting DNA aptamers using an evolution-mimicking algorithm. Nucleic Acids Res 2005, 33, e108e108.

14. Mazurov, A. V.; Titaeva, E. V.; Khaspekova, S. G.; Storojilova, A. N.; Spiridonova, V. A.; Kopylov, A. M.; Dobrovolsky, A. B. Characteristics of a new DNA aptamer, direct inhibitor of thrombin. Bull Exp Biol Med 2011, 150, 422-425.

15. Spiridonova V. A., Glinkina K. A., Gainutdinov A. A. Arutyunyan A. M. Production of thrombin complexes with DNA aptamers containing G-quadruplex and different duplexes. JNephrol Ther 2014, 4, 3-6.

16. Russo Krauss, I.; Spiridonova, V.; Pica, A.; Napolitano, V.; Sica, F. Different duplex/quadruplex junctions determine the properties of anti-thrombin aptamers with mixed folding. Nucleic Acids Res 2016, 44, 983-991.

17. Spiridonova, V. A.; Barinova, K. V.; Glinkina, K. A.; Melnichuk, A. V.; Gainutdynov, A. A.; Safenkova, I. V.; Dzantiev, B. B. A family of DNA aptamers with varied duplex region length that forms complexes with thrombin and prothrombin. FEBS Lett 2015, 589, 2043-2049.

18. Nielsen, P.; Dreioe, L. H.; Wengel, J. Synthesis and evaluation of oligodeoxynucleotides containing acyclic nucleosides: introduction of three novel analogues and a summary. Bioorg Med Chem 1995, 3, 19-28.

19. Kotkowiak, W.; Lisowiec-Wachnicka, J.; Grynda, J.; Kierzek, R.; Wengel, J.; Pasternak, A. Thermodynamic, anticoagulant, and antiproliferative properties of thrombin binding aptamer containing novel UNA derivative. Mol Ther Nucleic Acids 2018, 10, 304-316.

20. Langkjaer, N.; Pasternak, A.; Wengel, J. UNA (unlocked nucleic acid): a flexible RNA mimic that allows engineering of nucleic acid duplex stability. Bioorg Med Chem 2009, 17, 5420-5425.

21. Pasternak, A.; Wengel, J. Thermodynamics of RNA duplexes modified with unlocked nucleic acid nucleotides. Nucleic Acids Res 2010, 38, 6697-6706.

22. Singh, S. K.; Koshkin, A. A.; Wengel, J.; Nielsen, P. LNA (locked nucleic acids): synthesis and high-affinity nucleic acid recognition. Chem Comm 1998, 455-456.

23. Koshkin, A. A.; Singh, S. K.; Nielsen, P.; Rajwanshi, V. K.; Kumar, R.; Meldgaard, M.; Olsen, C. E.; Wengel, J. LNA (Locked Nucleic Acids): synthesis of the adenine, cytosine, guanine, 5methylcytosine, thymine and uracil bicyclonucleoside monomers, oligomerisation, and unprecedented nucleic acid recognition. Tetrahedron 1998, 54, 3607-3630.

24. Kumar, R.; Singh, S. K.; Koshkin, A. A.; Rajwanshi, V. K.; Meldgaard, M.; Wengel, J. The first analogues of LNA (Locked Nucleic Acids): phosphorothioate-LNA and 2'-thio-LNA. Bioorg Med Chem Lett 1998, 8, 2219-2222. 
25. Virno, A.; Randazzo, A.; Giancola, C.; Bucci, M.; Cirino, G.; Mayol, L. A novel thrombin binding aptamer containing a G-LNA residue. Bioorg Med Chem 2007, 15, 5710-5718.

26. D'Alonzo, D.; Guaragna, A.; Palumbo, G. Exploring the role of chirality in nucleic acid recognition. Chem Biodivers 2011, 8, 373-413.

27. Szabat, M.; Gudanis, D.; Kotkowiak, W.; Gdaniec, Z.; Kierzek, R.; Pasternak, A. Thermodynamic features of structural motifs formed by beta-L-RNA. PLoS One 2016, 11, e0149478.

28. Mergny, J. L.; Lacroix, L. Analysis of thermal melting curves. Oligonucleotides 2003, 13, 515537.

29. Campbell, M. A.; Wengel, J. Locked vs. unlocked nucleic acids (LNA vs. UNA): contrasting structures work towards common therapeutic goals. Chem Soc Rev 2011, 40, 5680-5689.

30. Kierzek, E.; Ciesielska, A.; Pasternak, K.; Mathews, D. H.; Turner, D. H.; Kierzek, R. The influence of locked nucleic acid residues on the thermodynamic properties of 2'-O-methyl RNA/RNA heteroduplexes. Nucleic Acids Res 2005, 33, 5082-5093.

31. Martin, S. R.; Schilstra, M. J. Circular dichroism and its application to the study of biomolecules. Methods Cell Biol 2008, 84, 263-293.

32. Burge, S.; Parkinson, G. N.; Hazel, P.; Todd, A. K.; Neidle, S. Quadruplex DNA: sequence, topology and structure. Nucleic Acids Res 2006, 34, 5402-5415.

33. Del Villar-Guerra, R.; Trent, J. O.; Chaires, J. B. G-quadruplex secondary structure obtained from circular dichroism spectroscopy. Angew Chem Int Ed Engl 2018, 57, 7171-7175.

34. Spiridonova, V. A.; Novikova, T. M.; Nikulina, D. M.; Shishkina, T. A.; Golubkina, E. V.; Dyukareva, O. S.; Trizno, N. N. Complex formation with protamine prolongs the thrombin-inhibiting effect of DNA aptamer in vivo. Biochimie 2018, 145, 158-162.

35. Mergny, J. L.; Li, J.; Lacroix, L.; Amrane, S.; Chaires, J. B. Thermal difference spectra: a specific signature for nucleic acid structures. Nucleic Acids Res 2005, 33, e138.

36. Crawley, J. T.; Zanardelli, S.; Chion, C. K.; Lane, D. A. The central role of thrombin in hemostasis. J Thromb Haemost 2007, 5 Suppl 1, 95-101.

37. Patching, S. G. Surface plasmon resonance spectroscopy for characterisation of membrane protein-ligand interactions and its potential for drug discovery. Biochim Biophys Acta 2014, 1838, 4355 .

38. Agarwal, T.; Kumar, S.; Maiti, S. Unlocking G-quadruplex: effect of unlocked nucleic acid on G-quadruplex stability. Biochimie 2011, 93, 1694-1700.

39. Roy, S.; Caruthers, M. Synthesis of DNA/RNA and their analogs via phosphoramidite and $\mathrm{H}-$ phosphonate chemistries. Molecules 2013, 18, 14268-14284.

40. Kotkowiak, W.; Kotkowiak, M.; Kierzek, R.; Pasternak, A. Unlocked nucleic acids: implications of increased conformational flexibility for RNA/DNA triplex formation. Biochem J 2014, 464, 203-211.

41. Lopez-Gomollon, S.; Nicolas, F. E. Purification of DNA Oligos by Denaturing Polyacrylamide Gel Electrophoresis (PAGE). In Methods Enzymol; Lorsch, J., Ed.; Elsevier,2013, 529, 65-83.

42. Mergny, J. L.; Lacroix, L. UV Melting of G-Quadruplexes. In Curr Protoc Nucleic Acid Chem 2009, 37, 17.1.1-17.1.15. 


\begin{tabular}{|c|c|c|c|c|}
\hline \multirow[b]{2}{*}{ Name } & \multirow{2}{*}{$\begin{array}{l}\text { Position of } \\
\text { modification }\end{array}$} & \multirow{2}{*}{$\begin{array}{c}\text { Sequence } \\
\left(5^{\prime}-3^{\prime}\right)\end{array}$} & \multicolumn{2}{|c|}{ Melting curve fits } \\
\hline & & & $\begin{array}{l}\mathbf{T}_{\mathrm{M}} \\
\left({ }^{\circ} \mathbf{C}\right)\end{array}$ & $\begin{array}{l}\Delta \mathbf{T}_{\mathrm{M}} \\
\left({ }^{\circ} \mathrm{C}\right)\end{array}$ \\
\hline RE31 & & GTGACGTAGGTTGGTGTGGTTGGGGCGTCAC $^{c}$ & $51.6 \pm 0.4$ & 0 \\
\hline $\mathrm{O} 1$ & $\mathrm{~T}^{11}$ & GTGACGTAGGU TGGTGTGGTTGGGGCGTCAC & $53.9 \pm 0.4$ & 2.3 \\
\hline $\mathrm{O} 2$ & $\mathrm{~T}^{15}$ & GTGACGTAGGTTGG $\underline{\mathbf{A}}^{\mathrm{v}}$ GTGGTTGGGGCGTCAC & $53.4 \pm 0.2$ & 1.8 \\
\hline $\mathrm{O} 3$ & $\mathrm{~T}^{15}$ & 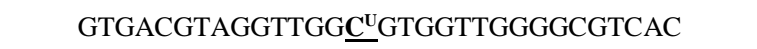 & $54.0 \pm 0.1$ & 2.4 \\
\hline $\mathrm{O} 4$ & $\mathrm{~T}^{15}$ & GTGACGTAGGTTGG $\underline{G}^{\mathbf{U}}$ GTGGTTGGGGCGTCAC & $54.2 \pm 0.3$ & 2.6 \\
\hline O5 & $\mathrm{T}^{15}$ & 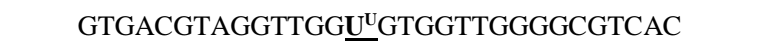 & $54.4 \pm 0.2$ & 2.8 \\
\hline O6 & $\mathrm{T}^{20}$ & GTGACGTAGGTTGGTGTGG $\underline{\mathbf{U}}^{\mathrm{U}} \mathrm{TGGGGCGTCAC}$ & $52.6 \pm 0.5$ & 1.0 \\
\hline O7 & $\mathrm{T}^{11}, \mathrm{~T}^{15}, \mathrm{~T}^{20}$ & GTGACGTAGG $\underline{\mathbf{U}}^{\mathrm{U}} \mathrm{TGG}^{\mathrm{U}} \underline{\mathbf{U}}^{\mathrm{U}} \mathrm{TGG}^{\mathrm{U}} \underline{\mathbf{U}}^{\mathrm{U}} \mathrm{TGGGGGTCAC}$ & $57.0 \pm 0.1$ & 5.4 \\
\hline O8 & $T^{2}, A^{4}, G^{6}, A^{8}$ & $\mathrm{G}^{\mathbf{T}^{\mathbf{L}}} \underline{\mathbf{A}}^{\mathbf{L}} C \underline{G}^{\mathbf{L}} \underline{\mathbf{A}^{\mathbf{L}} \text { GGTTGGTGTGGTTGGGGCGTCAC }}{ }^{c}$ & $62.4 \pm 0.4$ & 10.8 \\
\hline O9 & $T^{2}, A^{4}, G^{6}, A^{8}, T^{15}$ & 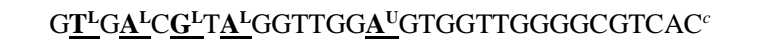 & $61.9 \pm 0.9$ & 10.3 \\
\hline $\mathrm{O} 10$ & $T^{2}, A^{4}, G^{6}, A^{8}, T^{15}$ & 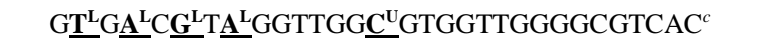 & $63.1 \pm 0.6$ & 11.5 \\
\hline O11 & $T^{2}, A^{4}, G^{6}, A^{8}, T^{15}$ & $\underline{G}^{\mathbf{L}} \underline{G}^{\mathbf{L}} C \underline{\mathbf{G}^{\mathbf{L}}} \underline{\mathbf{A}}^{\mathbf{L}}$ GGTTGG $^{\mathbf{G}^{\mathbf{U}}}$ GTGGTTGGGGCGTCAC $^{c}$ & $64.2 \pm 0.4$ & 12.6 \\
\hline $\mathrm{O} 12$ & $T^{2}, A^{4}, G^{6}, A^{8}, T^{15}$ & 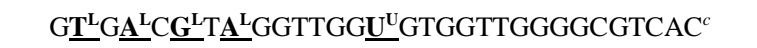 & $60.8 \pm 0.5$ & 9.2 \\
\hline O13 & $T^{2}-A^{8}, G^{24}-A^{30}$ & $\mathbf{G}^{\beta} \mathbf{G}^{\beta} \mathbf{A}^{\beta} \mathbf{C}^{\beta} \mathbf{G}^{\beta} \mathbf{U}^{\beta} \mathbf{A}^{\beta}$ GGTTGGTGTGGTTGG $\mathbf{G}^{\beta} \mathbf{G}^{\beta} \mathbf{C}^{\beta} \mathbf{G}^{\beta} \mathbf{U}^{\beta} \mathbf{C}^{\beta} \mathbf{A}^{\beta} \mathbf{C}$ & $53.2 \pm 0.2$ & 1.6 \\
\hline
\end{tabular}


Table 2. The anticoagulant properties (TT, AE $)^{\mathrm{a}}$, dissociation constant $\left(\mathbf{K}_{\mathbf{d}}\right)$ and biostability $\left(\mathbf{T}_{1 / 2}\right)$ of RE31 variants modified with UNA-A $\left(\underline{\mathbf{A}^{\mathrm{U}}}\right)$, UNA-C $\left(\underline{\mathbf{C}^{\mathrm{U}}}\right)$, UNA-G $\left(\underline{\mathbf{G}^{\mathbf{U}}}\right)$, UNA-U $\left(\underline{\mathbf{U}^{\mathbf{U}}}\right)$, LNA-A $\left(\underline{\mathbf{A}^{\mathbf{L}}}\right)$, LNA-G $\left(\underline{\mathbf{G}^{\mathbf{L}}}\right)$, LNA-T $\left(\mathbf{T}^{\mathbf{L}}\right), \beta-\mathrm{L}-\mathrm{RNA}-\mathrm{A}\left(\underline{\mathbf{A}^{\boldsymbol{\beta}}}\right), \beta-\mathrm{L}-\mathrm{RNA}-\mathrm{C}\left(\underline{\mathbf{C}^{\boldsymbol{\beta}}}\right), \beta-\mathrm{L}-\mathrm{RNA}-\mathrm{G}\left(\underline{\mathbf{G}^{\boldsymbol{\beta}}}\right)$ and $\beta$-L-RNA-U $\left(\underline{\mathbf{U}^{\boldsymbol{\beta}}}\right)$.

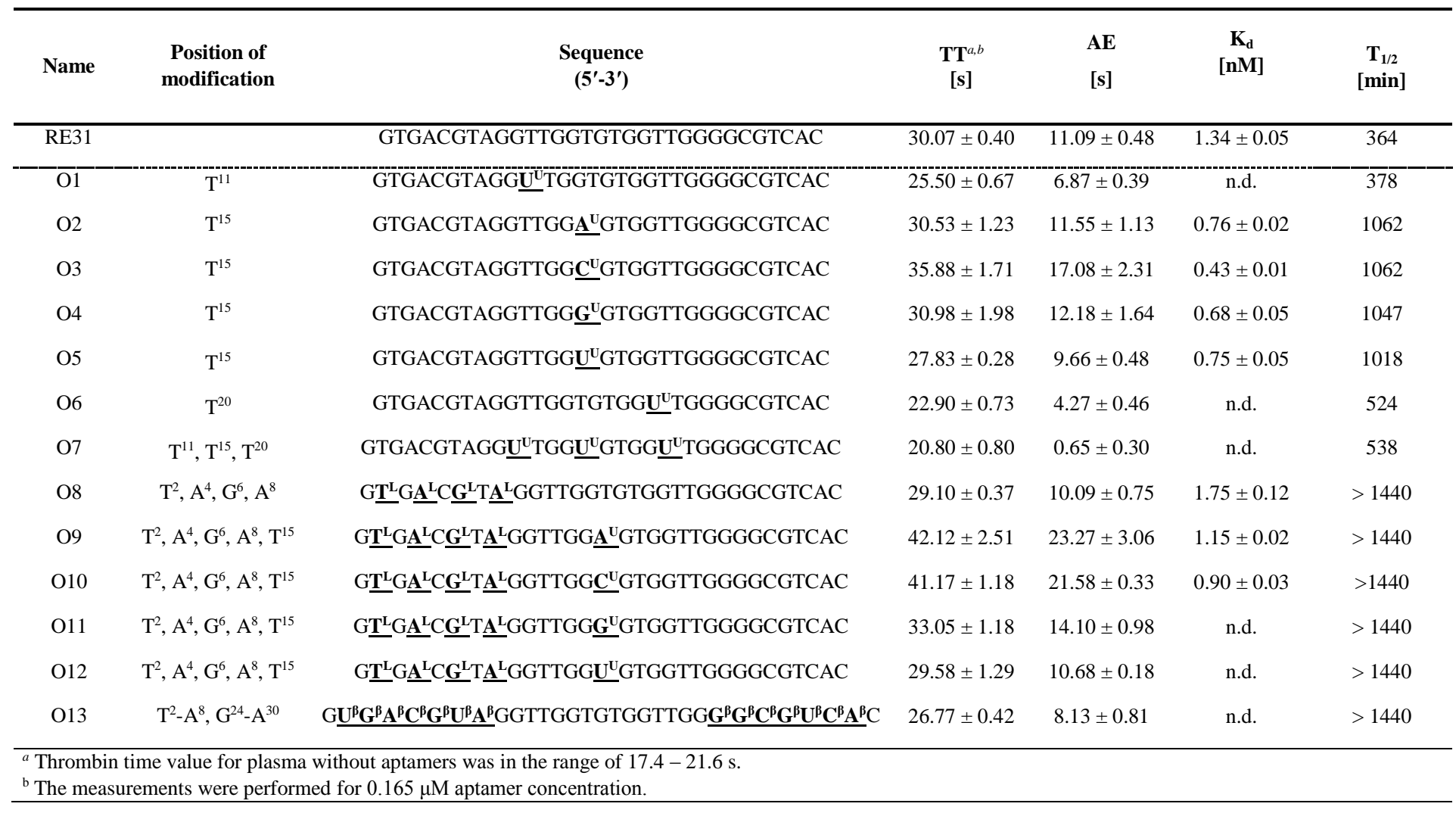


TABLE OF CONTENTS GRAPHIC

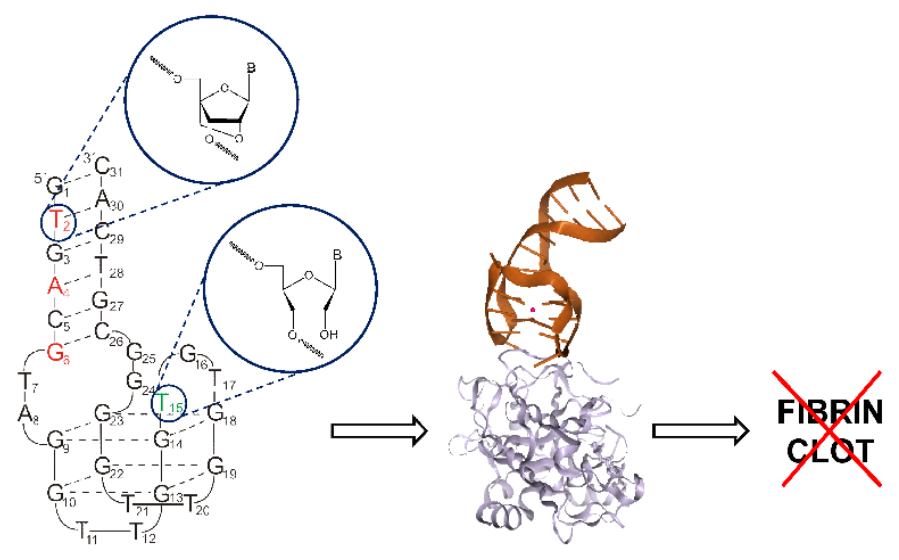

